\title{
THE ROLE OF NOTICING AND WORKING MEMORY CAPACITY IN L2 ORAL PERFORMANCE
}

\author{
Joara Martin Bergsleithner ${ }^{1}$
}

\begin{abstract}
This study investigates how noticing of L2 instances in input relates to working memory (WM) capacity and to grammatical accuracy in L2 oral tasks. Participants were 30 Brazilian adult learners of English who were required to perform five tasks aimed at assessing (a) WM capacity, (b) grammatical accuracy in oral performance, and (c) noticing of formal aspects of a target structure. The results show that there are statistically significant relationships among noticing of $L 2$ formal features, grammatical accuracy in L2 oral performance and WM capacity. Together, the results can be taken as evidence that learners with a larger WM capacity are also more prone to noticing $L 2$ formal aspects and to performing more grammatically accurate speech in the L2.
\end{abstract}

Key-words: noticing; working memory capacity; maintenance of L2 forms; L2 oral performance

\section{INTRODUCTION}

In the mainstream Second Language Acquisition (SLA) field, noticing and working memory (WM) capacity are two cognitive constructs

1 UnB.

Organon, Porto Alegre, nº 51, julho-dezembro, 2011, p. 217-243 
that may contribute to second language (L2) acquisition ${ }^{2}$ and maintenance of the information acquired, and distinguish individuals in oral tasks performance (Bergsleithner, 2007).

In order to understand how these cognitive constructs might affect individuals' L2 learning and L2 ${ }^{3}$ oral performance, one must first understand how these cognitive constructs trigger individual differences among humans when dealing with grammatical accuracy. This study has as theoretical foundations the studies on noticing and working memory capacity in SLA based upon the Noticing Hypothesis (Schmidt, 1990). In the concluding part these issues are discussed and directions for further research are suggested.

\section{THEORETICAL BACKGROUND}

Over the past years, several studies (e.g. Skehan, 1989, 1998; Robinson, 1995, 1997) have shown that individuals distinguish among themselves due to several cognitive constructs such as noticing and working memory (WM) capacity.

Some studies (Mackey, Philp, Fujii, Egi, \& Tatsumi, 2002; Robinson, 1995, 1996a, 1996b, 1997, 2001, among others) have investigated the Noticing Hypothesis, as proposed by Schmidt (1990), who claims that L2 learners need to notice L2 linguistic formal aspects in input in order to learn them. These studies have shown that individuals distinguish because of attentional processes they allocate to the L2 linguistic formal aspects in input.

Other studies have shown that individuals with a larger working memory capacity (higher spans/higher processors) demonstrate better performance on complex cognitive tasks, since they efficiently allocate their attentional cognitive processes demanded by a task. On the other hand, others have shown that individuals with smaller WM capacity (lower spans/lower processors) seem to allocate these processes in a less efficient way (Bergsleithner, 2007; Daneman \& Carpenter, 1980, 1983; Daneman \& Green, 1986; Fortkamp, 1999, 2000; Just \& Carpenter, 1992; Miyake, Just, \& Carpenter, 1994; Miyake \& Friedman, 1998; Miyake \& Shah, 1999; Shah \& Miyake, 1996).

2 The theoretical terms acquisition and learning will be used interchangeably throughout the whole text.

3 The terms second and foreign language will be also used interchangeably. 
Working memory capacity is conceptualized in this study as a cognitive construct that refers to: (a) the system or mechanism responsible for storage and processing of information during performance of complex cognitive tasks (Baddeley, 1986, 1990; Baddeley \& Hitch, 1974; Daneman \& Carpenter, 1980; Harrington, 1992; Harrington \& Sawyer, 1992; Shah \& Miyake, 1996), such as oral production, among others; (b) "the relative capacity to intake and integrate information in immediate, online processing" (Harrington, 1992, p. 123); (c) "the mechanism of retrieval and maintenance of information during cognitive processing" (Watanabe \& Bergsleithner, 2006, p. 47); and (d) "the storage and processing of information and the processes of recall and maintenance of the information acquired" (Bergsleithner, 2007, p. 38).

Noticing is first conceptualized as Schmidt (1990) claimed in his Noticing Hypothesis, that learners need to notice L2 linguistic aspects in input in order to acquire them. For him, noticing is a personal experience of a conscious knowledge one has in input about any linguistic aspects (Bergsleithner, 2009). However, some studies (e.g. Ellis's, 1990, 1993, 1994, 1999, 2001) suggested that noticing of L2 formal aspects may be facilitated by instruction. Other studies have shown that noticing might take place in a subsequent input after instruction (Bergsleithner \& Frota, forthcoming; Robinson, 1995, 1996a, 1996b, 1997; Schmidt \& Frota, 1986). Ellis and Schmidt (1997) claimed that input frequency and task repetition are beneficial for noticing. Bergsleithner (2007) suggested that noticing might also be seen as a crucial cognitive construct that triggers L2 learning in different settings, works simultaneously with WM capacity, and is related to sustained performance. For her,

noticing is a psychological construct conducted by working memory capacity. Through noticing, learners can register linguistic input in instructional and/or non-instructional settings. In addition, noticing is also related to sustained performance (p. 38).

So far, there have been still few studies about (a) the relationship between noticing and WM capacity (Bergsleithner, 2007; Mackey et al, 2002; Robinson, 1995, 1996a, 1996b, 1997, 2001, 2002a), and perhaps only one on (b) WM, noticing of interactional feedback and L2 devel- 
opment (Mackey et al, 2002), and one on (c) Feedback, Noticing and Instructed Second Language Learning (Mackey, 2006). Thus, a better understanding of the relationships among WM capacity, noticing, and L2 oral performance might facilitate an explanation for learners' individual differences when learning an L2 (Bergsleithner, 2007). Other studies (Mackey et al., 2002; Robinson, 1995, 1996a, 1996b, 1997, 2001, among others) have investigated the Noticing Hypothesis and showed that noticing L2 linguistic aspects or instances of a grammatical structure in input makes individuals learn the L2.

For Robinson (1995, 1996a, 1996b, 1997, 2001), noticing is closely related to WM capacity, and WM could constrain noticing. For Mackey et al. (2002), noticing through interactional feedback could be guided and constrained by WM capacity. Although Mackey et al. (2002) claim that noticing is related to WM capacity, they claim that noticing is not related to WM capacity alone, but to other factors such as "grammatical sensitivity and field independency, as well as socio-psychological factors" (p. 202). Harrington and Sawyer (1992) have also shown that grammatical sensitivity is closely related to WM capacity.

Furthermore, Bergsleithner (2007, p. 112), claimed that, besides grammatical sensitivity, some factors could constrain noticing such as (a) the lack of familiarity with the task; (b) the lack of motivation in doing the task or in participating in the research; (c) the high degree of the participants' anxiety to be recorded in language labs; and also (d) the lack of interest in knowing about any grammar structures.

Other researchers (Fortkamp, 1999, 2000; Fortkamp \& Bergsleithner, 2007; Payne \& Ross, 2005; Payne \& Whitney, 2002) have shown in their findings that working memory capacity is closely related to $\mathrm{L} 2$ oral production. Thus, noticing and maintenance of L2 aspects in the performance of L2 oral tasks may be related to WM capacity and possibly to other variables.

\section{METHOD}

\section{Research Questions:}

1) Are there relationships among WM capacity, noticing of L2 forms, and $\mathrm{L} 2$ oral performance?

2) Is WM capacity related to noticing? 
3) Is WM capacity related to L2 oral performance?

4) Is noticing related to $L 2$ oral performance?

5) Is accuracy in oral performance of the target structure statistically different in the pretest phase and in the posttest phases? If so, is this difference related to WM capacity and/or noticing?

\section{Research Hypotheses:}

Hypothesis 1: Individuals with a larger WM capacity, as measured by the SST, notice more L2 formal aspects in input and have a more accurate grammatical performance of the target structure in the two oral posttests (immediate and delayed) after treatment. In contrast, individuals with smaller WM capacity notice fewer L2 formal aspects and make more inaccuracies in those oral tasks.

Hypothesis 2: Individuals with a larger WM capacity have more ability to recall what was noticed -- the target structure -- in their episodic memory. Hypothesis 3: There is a significant improvement in grammatical accuracy in the performance of the target structure in the pretest phase compared to the immediate posttest phase after treatment. However, there is some weakening of accuracy in oral performance of the target structure in the delayed posttest compared to the immediate posttest due to the difficulty of maintenance of the target structure.

\section{Participants}

This study was carried out with a group of 30 adult English students, native speakers of Brazilian Portuguese, who were learning English as a Foreign Language (EFL). They ranged in age from 18 to 43 years old, with a mean of 25 years, being 17 male and 13 female, and came from a University in the South of Brazil. They were studying lesson 2 of the book adopted for this course - New Interchange 2 (Richards, Hull, \& Proctor, 2002). In addition, an experimenter, an English teacher, an American rater, and four Applied Linguistics/English $\mathrm{PhD}$ raters participated in this study.

\section{Materials and tasks for data collection}

The experiment consisted of five tasks. One task aimed at assessing WM capacity through the Speaking Span Test (SST) (Daneman, 1991; Daneman \& Green, 1986; Fortkamp, 1999, 2000), three oral tasks aimed 
at assessing accuracy ${ }^{4}$ through the participants' oral performance of six Indirect Questions in each task, and one task aimed at assessing noticing through an oral protocol (Bergsleithner, 2007).

\section{The Speaking Span Test (SST)}

The SST was proposed by Daneman and Green (1986) and Daneman (1991) for L1 studies, and adapted by Fortkamp (1999) for L2 studies. Fortkamp $(1999,2000)$ suggested that this kind of test aims at assessing individuals' WM capacity in L2 speech production, while Daneman and Green (1986), and Daneman (1991) assessed individuals' WM capacity in L1. Following Fortkamp (1999, 2000), this test consists of 60 unrelated nouns, organized in sets of 2 to 6 words, which were read by the participants aloud. Each word in bold was individually presented for one second in the center of a computer screen. At the end of each set of 2 to 6 words, 2 to 6 question marks appeared respectively in the middle of the computer screen to inform the participants that the set had finished. The number of question marks indicated the number of words presented in each set. Then, the participants were asked to produce a sentence aloud for each word presented. For example, after being presented with the following set of 2 words:

\section{People \\ Earth \\ ??}

E.g.: One produced sentences as follows: People are beautiful. The Earth is being killed.

The sentences produced should contain the words presented in their original form and order of presentation (as for instance, people/ earth; soccer/wife/power), and they should be grammatically accurate to be scored. However, even if the utterances were grammatically accurate, they were not scored if the words were produced differently from their original form or order of presentation. The sentences were judged as accurate or inaccurate by following the parameters established by this researcher and a native speaker of American English in order to assess WM capacity within grammatical accuracy in the sentences produced, two kinds of WM scores - WM-strict (for sentences

4 In this study grammatical accuracy was assessed in the utterances by analyzing the target structure only in order to avoid assessing complexity as well. 
were grammatically accurate with some pragmatic competence and some naturalness or native-likeness), and WM-lenient scores (for sentences grammatically correct, although they were not properly used or native-like as native speakers do).

\section{The performance of an L2 oral production task (pretest phase)}

Departing from 50 participants, 18 participants were eliminated of the study, since their level of proficiency in English ${ }^{5}$ was too high or too low. Then, thirty-two participants performed this task. They were instructed in Portuguese to use Indirect Questions and required to make 6 questions by looking at a picture of a map. There was a criterion to eliminate participants from this task -- participants were excluded in case they accurately produced the questions. After recording the participants' speech, the experimenter verified whether they could orally perform indirect questions or not.

The grammatical structure chosen for this study was part of the syllabus of the course in which the participants were engaged in. Out of 32 participants, 2 demonstrated previous knowledge on the target grammar structure, and then they were excluded from the study. Thus, 30 participants took part of this study.

\section{The Instructional Treatment and Procedure for the treatment}

The treatment was given by the teacher to instruct the participants to use Indirect Questions both in the immediate posttest, administered on the same day of the treatment, and in the delayed posttest, two weeks after treatment. Both posttests aimed at assessing whether the participants had noticed instances of the target grammar structure in the input of the instructional treatment. In addition, the delayed posttest aimed to verify whether they could maintain those instances of the target structure for a longer period of time.

The kind of treatment was the Form-focused Instruction ${ }^{6}$, as proposed by Ellis (2001). In the beginning of the instruction, the partici-

5 A picture description task aimed at verifying the participants' English proficiency level in order to obtain a more homogenous group was applied. Four raters (English $\mathrm{PhD}$ students) judged the participants' accuracy on a scale of 0 to 5 , following a rating scale adapted from the FCE Speaking Test Assessment Scales (Cambridge Examination), Iwashita, McNamara and Elder (2001), and the RSA test (in Hughes, 1989).

6 "The term Form-Focused Instruction (FFI) is used to refer to any planned or incidental instruction activity that it is intended to induce language learners to pay attention to linguistic form (Ellis, 2001, p. 1). 
pants were induced to learn some specific formal aspects of Indirect Questions (the embedded questions) ${ }^{7}$, which were part of the syllabus. This structure seems to be more complex than others and to demand more cognitive effort from the participants, distinguishing, thus, higher from lower processors.

The instruction was initially given by inductive teaching calling the learners' attention to the specific form with the following warm up: (a) how would you ask information about directions on the streets?; (b) what kind of questions would you use to ask other people about directions or any other information?; (c) how would you ask a friend about directions?; (d) how would you ask an unknown person about anything?; (e) how would you ask polite questions?; (f) in which situations would you use indirect questions?; (g) how would you make indirect questions?

After the warm-up session ${ }^{8}$, the participants were asked about the situations in which indirect rather than direct questions are more properly used. Then, they were told to: (a) give oral examples of indirect questions to the participants; (b) ask participants to practice indirect questions in pairs for a few minutes; and finally, (c) follow instructions of their text book (Richards et. al, 2002, p. 11). Finally, the target structure was written on the board to explicitly show them the modifications in the position of the verb when comparing the structure of direct and indirect questions, the use and position of the auxiliary verbs, and the main verbs in both kinds of questions.

\section{Posttests Phases}

The immediate posttest was carried out in two steps: (a) the oral protocol collection, in which the participants were asked some questions in the language laboratory (lab) (see appendix A); and (b) the performance of an L2 oral task, in which the participants were asked to make 6 indirect questions again, the same task but with different

7 The embedded questions require a complex language process from the participants, that is, to elaborate a question embedded into the other (Bergsleithner, 2007).

8 In the warm up session the participants were told that when individuals are very close friends they usually ask each other some direct questions such as What time is it?, Where is the supermarket?, Where is the university?, What time does the bank close?, How much is this or that?. On the other hand, when individuals are not very close or do not know each other, they usually ask the questions above in a more formal or polite way such as Do you know what time it is?, Can you tell me where the supermarket is? Could you tell me where the university is? Do you know what time the bank closes? 
pictures. The participants were required to make the questions about a picture of a map, as the task required in the pretest.

The delayed posttest was carried out in just one moment in time, two weeks after treatment. Over again, the participants were asked to make 6 indirect questions while looking at a picture of a map. This posttest was administered to verify whether grammatical accuracy of the target structure was consistently used in the participants' L2 oral performance two weeks later. In other words, it verified whether the participants maintained the same degree of accuracy in the specific formal aspects in the oral performance of the delayed phase as compared to the immediate posttest phase.

\section{The Oral Protocol (Immediate Posttest)}

The oral protocol aimed at assessing the learners' noticing of instances of the Indirect Questions structure, which they had been taught. Robinson's (1995) framework (whether learners notice any rules, look for rules, and verbalize rules) was used as a guide to elaborate the questions for the oral protocol as well as to analyze the learners' answers. One more question (whether they could remember the target grammar structure which they had been taught and whether they could explain how such target grammar structure was organized in Indirect Questions), and an oral task (to orally perform 2 indirect questions by using the target structure) were added to the oral protocol by this researcher (see Appendix A for question number 3, and the oral task number 5).

Although Robinson's framework was followed, Bergsleithner (2007) acknowledges that looking for rules is a weak measure of noticing for two reasons. First, because looking for rules is a statement about what one does when speaking, i.e., producing utterances, possibly with the help of explicit knowledge, not about how one learns or gets that knowledge. Secondly, looking for rules is not the same as finding them. Thus, someone answering "yes" to this question in the oral protocol does not guarantee that this person has necessarily noticed anything (Bergsleithner, 2007, p. 72). Therefore, in order to see if looking for rules made any difference in the outcome, the participants' noticing was scored in the two following ways: (a) Noticing 1, in which Robinson's second question (Do you look for rules?) was not included, and (b) Noticing 2, in which Robinson's second question (Do you look for rules?) was included to score the measure of noticing (see the oral protocol - Appendix A).

Organon, Porto Alegre, nº 51, julho-dezembro, 2011, p. 217-243 


\section{Assessment of noticing through the oral protocol}

An indirect measure of noticing was assessed by recalling from episodic memory the linguistic aspects of the target structure that learners noticed in input through the instructional treatment. This recalling of noticing was called here retrospective accounts, based on Ericsson's and Simon's studies $(1980,1993)$. Noticing was assessed by means of the oral protocol, which elicited the participants' uptake'. Noticing, thus, was indirectly measured off-line ${ }^{10}$ by means of uptake in the oral protocol, immediately after the instructional treatment (see the scores for assessing noticing - Appendix B).

\section{The Oral Tasks (Immediate and Delayed Posttest)}

A new recording was made at the language lab immediately after the oral protocol, which was after the instructional treatment, to verify whether the participants noticed instances of the target structure they were instructed through treatment and whether they could orally perform the target structure. Thus, a new picture of a map was selected for the participants to use such structure in order to minimize the effects of task repetition in oral performance, following Bygate (2001) and Skehan (1996).

The delayed posttest was carried out in only one phase two weeks after the treatment. A new recording was collected with the same task in the language lab; however, with a different map picture. This final language lab recording aimed at verifying whether the participants could (a) notice instances of indirect questions during treatment, (b) perform indirect questions in a delayed phase, and (c) sustain grammatical accuracy in performing indirect questions two weeks after treatment.

\section{Assessment of the participants' accuracy in the performance of Indi- rect Questions in the three oral tasks}

Some parameters ${ }^{11}$ were used to judge whether the sentences pro-

9 The theoretical term uptake in this study means what the participants think they learned and what they were aware of, and also what they can verbalize - the target structure, in this case (based on Lowen, 2004)

10 I consider, throughout this study, the term off-line as an instant after input, and on-line as the moment in the input.

11 Some parameters for scoring the participants' oral performance were established with the presence of a native speaker of American English, a $\mathrm{PhD}$ candidate from the Second Language Studies Department, at the University of Hawaii at Manoa in the U.S., who also assisted this researcher to judge the accuracy of the participants in the Speaking Span Test scores. 
duced by the participants, by means of elicitation of $\mathrm{L} 2$ oral production tasks, were accurate or not. The parameters were divided into three different general categories: (1) Errors for the sentences which were considered totally inaccurate concerning the target structure; (2) Small mistakes for the sentences which were not considered as errors, since the participants properly used the target grammatical structure; (3) Very accurate sentences for those accurate and coherent sentences which contained the target structure and did not have any kind of grammar mistakes (see appendix C for all the three categories).

\section{RESULTS AND DISCUSSION}

Table 1 indicates that in the three oral performance (OP) tasks (here called tests) there was a sizeable difference in the mean learner performance between OP1 and OP2, and OP1 and OP3, that is, before and after treatment. However, as it can be seen in Table 1, there is a similarity in the mean learner performance between OP2 and OP3, both tests after treatment, although the first was immediate and the second delayed.

In addition to the oral performance tests, the descriptive statistics in Table 1 point to the two scores for the measures of working memory capacity (WM-strict and WM-lenient), and the two scores obtained for noticing 1 (N1) and noticing 2 (N2), through the oral protocol. The correlations between the scores of these variables are better explained in Table 2, which displays the results for working memory capacity and noticing.

\begin{tabular}{|c|c|c|c|c|c|c|c|}
\hline & N & Minimum & Maximum & Mean & SD & Skewness & Kurtosis \\
\hline OP1 & 30 & 0 & 3 & 0.97 & 1.12 & 0.83 & -0.69 \\
\hline OP2 & 30 & 1 & 12 & 7.27 & 2.79 & -0.28 & -0.32 \\
\hline OP3 & 30 & 0 & 12 & 7.17 & 3.35 & -0.76 & -0.18 \\
\hline WMS & 30 & 5 & 34 & 18.50 & 5.93 & 0.10 & 0.69 \\
\hline WML & 30 & 6 & 35 & 19.46 & 6.08 & 0.16 & 0.56 \\
\hline N1 & 30 & 2 & 9 & 6.40 & 2.04 & -0.66 & -0.70 \\
\hline N2 & 30 & 2 & 10 & 7.50 & 2.31 & -0.96 & 0.08 \\
\hline
\end{tabular}

Table 1. Descriptive statistics for the variables of the study: Oral performance, noticing and working memory capacity

As shown in Table 1, while OP1 shows the mean performance of 0.97 and a standard deviation $(S D)$ of 1.12 , these scores are minimal to show significance. However, performances in OP2 and OP3 show 
a considerable difference in the mean scores of participants, OP2 with a mean of 7.27, and a $S D$ of 2.79 , and OP3 with a mean of 7.17 and a $S D$ of 3.35. These results indicate that there was a large change in the mean scores of this test, from the pretest to the posttests. There was also considerable variability in performance within the group. Despite individual variability, it can be seen that there was a large overall difference between performance with the target structure before and after treatment. This finding suggests that there was noticing of formal aspects of the target structure and some language development, since participants could accurately produce oral sentences using such structure.

Moving on to Table 2, correlation findings are displayed among the measures of all variables: (a) oral performance (grammatical accuracy in oral performance); (b) working memory capacity; and (c) noticing. Pearson correlations were calculated among the two measures of working memory (WM-strict and WM-lenient), the two measures of noticing ( 11 and $\mathrm{N} 2$ ), and oral performance scores on the three testing occasions (OP1, OP2, OP3). A two-tailed alpha decision level of $p<.05$ was set for all inferential decisions of statistical significance for the correlations. Table 2, as follows, displays the correlation findings.

\begin{tabular}{|c|c|c|c|c|c|c|c|}
\hline & Oral P1 & Oral P2 & Oral P3 & WM-strict & WM-lenient & N1 & N2 \\
\hline WM-strict & 0.15 & ${ }^{*} 0.61$ & ${ }^{*} 0.64$ & - & - & - & - \\
\hline WM-lenient & 0.17 & ${ }^{*} 0.61$ & ${ }^{*} 0.63$ & ${ }^{*} 0.99$ & - & - & - \\
\hline N1 & 0.26 & ${ }^{*} 0.60$ & ${ }^{*} 0.70$ & ${ }^{*} 0.41$ & ${ }^{*} 0.42$ & - & - \\
\hline N2 & ${ }^{*} 0.38$ & ${ }^{*} 0.59$ & ${ }^{*} 0.72$ & ${ }^{*} 0.42$ & ${ }^{*} 0.43$ & ${ }^{*} 0.95$ & - \\
\hline
\end{tabular}

Table 2. Pearson correlations between oral performance scores, working memory capacity, and noticing

Several findings are apparent in Table 2. First, for these correlational comparisons, the choice of strict versus lenient WM measures makes little difference. The two measures are very highly correlated $(r=.99)$, and correlations with the oral tests change by only a few decimal points if at all, based on the strict versus lenient WM scoring. Second, the choice of $\mathrm{N} 1$ versus $\mathrm{N} 2$ as the measure of noticing does not make much difference for comparisons with measures of WM capacity, nor for comparisons with either the immediate posttest or the delayed posttest. However, there is a larger difference between the N1 and N2 correlations with the pretest $(r=.26$ versus $r=.38$, respectively). Notice also 
that, although there is some degree of relationship between $\mathrm{N}$ and $\mathrm{WM}$ capacity, it is not particularly strong (around $r=.42$ ), suggesting that these two measures are tapping distinct constructs.

Moving on to the immediate posttests, where WM capacity and noticing would be presumed to exhibit some kind of influence (if they are indeed related to oral test performance), there is a clear, if moderate, relationship between both the WM capacity and noticing variables and the oral tests performance, ranging almost imperceptibly for each between $r=.59$ to $r=.61$. Perhaps of most interest, moving to the delayed test, the strength of relationships increases for both the WM and N variables. However, a much larger increase is apparent for noticing (for N1, from $r=.60$ on the post-test to $r=.70$ on the delayed test). These findings suggest that, while both working memory and noticing are moderately related to immediate test performance (and by extension, perhaps, to the learning that was required to perform well), noticing is slightly more strongly related to sustained performance on the delayed test.

\section{Inferential statistics: Oral performance results}

The descriptive findings presented above suggest apparent patterns in the participants' oral performance before and after treatment. However, in order to examine the statistical trustworthiness of apparent observed differences between the three testing occasions (see Table 2), one repeated measures analysis of variance (ANOVA) was performed with pretest, immediate posttest, and delayed posttest as the three levels of the within-subjects variable. The alpha level was set at $p<.05$ for the inferential decision of statistical significance.

In addition, the differences between OP1 and OP2, and OP1 and OP3 are all statistically significant since they show a considerable progress in the mean performance regarding the scores of grammatical accuracy in the sentences produced by the participants, while using the specific target structure in the three testing occasions. Moreover, an overall statistically significant effect was found for "test", Wilks' lambda $F(2,28)=86.09, p=.000$. A very high eta-squared effect size $(0.86)$ indicated that "test" accounted for a very large proportion of the overall difference between the three sets of scores (i.e., overall, there was considerable magnitude of difference between the testing occasions).

From the overall statistically significant effect for "test", subsequent pairwise comparisons were also conducted between each of the three 
pairs of tests (OP1, OP2, OP3). Statistically significant differences were found between the pretest and the immediate posttest $(p=.000)$, and between the pretest and the delayed posttest $(p=.000)$, but not between the two posttests $(p=.766)$. Apparently, the learners changed in substantially and statistically trustworthy degrees from the pretest to the posttest, but there was little perceptible change from posttest to delayed test.

Thus, the results suggest that there are statistically significant relationships among WM capacity, noticing of L2 linguistic aspects, and L2 oral performance. Based on these findings, Hypothesis 1 was supported because most of the higher spans (the ones who obtained higher WM scores in the Speaking Span Test - SST) when compared to the lower spans (the ones who obtained lower WM scores in the SST) showed to be better at noticing the L2 formal aspects of the target structure. Moreover, the higher spans orally performed questions using the target structure more accurately. On the other hand, most of the lower spans could neither notice nor orally produce language using the target rule with the same accurate performance as the higher processors.

However, there were two exceptions among the higher spans. Participant 15 (P15) did not notice instances of the target structure nor could accurately produce it. And P21 could notice instances of the target structure but he could not orally produce it. Thus, what happened to P15? He informed that he has lived a year abroad, in the United States. Because of that, he is probably more willing to learn languages within interactional settings with native speakers rather than being instructed in a classroom. He is possibly more inclined to notice online L2 linguistic aspects without instruction through interactional conversations. Therefore, his ability to recall and retrieve the target structure could have been constrained by the task in the lab as well as by the method of the instructional treatment.

And what happened to P21? He could not accurately perform the oral tasks in the three testing occasions. It probably happens due to some psychological factors (as Mackey et al. (2002) proposed), which probably may also constrain noticing or accurate oral performance. Perhaps he lacked familiarity with the task in the language lab, or still lacked interest in learning the specific targeted structure or any other grammatical structures (Bergsleithner, 2007).

Finally, another pertinent question to this hypothesis is related to whether all lower spans notice the target structure or not. Just a few of 
the participants noticed instances of the target structure, although with different scores. Besides the WM capacity limit, other factors could have constrained noticing for the lower spans in this study, such as grammatical sensitivity. This corroborates Harrington's (1992) findings that working memory is closely related to grammatical sensitivity and also Bergsleithner's (2007) suggestion that some factors may constrain noticing such as: (a) the lack of familiarity with the task, since the task was carried out at the language lab; (b) the lack of motivation in doing the task as well as in participating in the research; (c) the high degree of the participants' anxiety to be recorded; and (d) the lack of interest in knowing the target structure or any other grammar structures.

In response to the second and the third questions of whether (a) changes happen with instructional treatment, (b) accuracy in oral performance seems to be better after treatment, and (c) immediate differences after treatment last, the results suggest that there was a statistically significant improvement in grammatical accuracy between tests. Specifically, there is a significant difference between tests 1 and 2, and tests 1 and 3, while the difference between tests 2 and 3 was not statistically significant because grammatical accuracy remained relatively constant in both tests. This finding in the mean learner performance between OP2 and OP3 consistently indicates maintenance in the accuracy scores for two weeks after treatment.

Hypothesis 2, therefore, was supported since grammatical accuracy in the performance of oral tasks was presented in the posttest phases, after treatment condition, and also because the participants could verbalize the target structure as well as maintain it for two weeks. Such verbalization was obtained by means of uptake in the oral protocol by recalling noticing. That does not imply, however, that if a speaker is not successful to produce uptake, the linguistic form was not noticed in input. Other factors may be related to this fail, such as: (a) the language processing between input and output in language development; (b) the level of cognitive processing the participants had to engage in; and (c) the cognitive individual differences that the participants present in the process of acquiring a second language (Bergsleithner, 2007).

Although Loewen (2004) has advocated that "noticing/learning" is possible without the production of uptake, the fact that the participants produced utterances closely to the targeted structure (although not ac-

Organon, Porto Alegre, nº 51, julho-dezembro, 2011, p. 217-243 
curate as they should be) offered some reasons to believe that noticing occurred and that learners are in a stage of learning. Most participants were able to verbalize the target structure and give examples after treatment. Once more, in general, the higher spans performed more accurately than the lower spans.

Hypothesis 3 was also supported since there was some weakening of accuracy in oral performance of the target structure in the delayed posttest compared to the immediate posttest, due to the difficulty of maintenance of the target structure, which is related to the constraints of WM capacity and noticing. However, maintenance of the target rule occurred and sustained for two weeks. This entails that noticing occurred in input (during online instructional treatment), and then, it was indirectly recalled two weeks later. Such maintenance must have probably occurred because of noticing, which made learners aware of the target structure and also contributed to the process of recalling the structure by means of uptake. This implies that accuracy is maintained in the oral performance tasks, due to noticing, as well as supported by the mechanisms of recall and retrieval, which are carried out by working memory capacity.

Moreover, working memory had the crucial role in the process of recall of noticing, especially when the participants had to use the target structure in the delayed posttest. Furthermore, the frequency effect of task repetition was quite positive to the participants' maintenance and retrieval of the target structure after two weeks (Bygate, 2001). The occurrence of noticing was the main reason for maintenance, although task repetition has probably contributed to the recalling of noticing, and thus, to the participants' maintenance of the target structure for a longer period of time (Bygate, 2001; Skehan, 1996).

\section{CONCLUSION}

The results of this study corroborate Schmidt's $(1990,1995,2001)$ and Robinson's (1995, 1996b, 1997, 2001, 2002) suggestions that WM is closely related to noticing, and that noticing could be constrained by WM capacity (Robinson, 1997, 2001), and also Cowan's (1988) assumption that WM is closely related to attention and awareness. Moreover, the results corroborate Fortkamp's (1999) Payne and Ross's (2005), 
and Payne and Whitney's (2002) findings that WM correlates with L2 oral production. Still, the results show rationale with other researchers' proposals, as for example, with Ellis's $(1993,1994,1999)$ suggestion that noticing instances of L2 forms during instruction may facilitate L2 learning, and thus enhance grammatical accuracy in L2 oral production, and improve language development (Fortkamp \& Bergsleithner, 2007; Robinson, 1995, 1996, 2001), and with Harrington and Sawyer (1992) and Mackey et al. (2002) that grammatical sensitivity is closely related to working memory capacity. These findings reveal that individual differences in WM capacity are closely related to grammatical accuracy of L2 oral performance.

This study presented some limitations. Due to the limited number of participants, it was not possible to do a regression analysis in order to see which variable predicted better in this study. Further research should do that by replicating this study, and then verify whether it is noticing or WM capacity the best accuracy predictor in oral performance.

Second, WM capacity was not assessed in L1, only in L2 since this research was conducted in L2, only. Further research should assess WM capacity both in L1 and L2 in order to verify whether there were differences or similarities in WM capacity in both languages, as measured by the SST, and whether the way in which the participants process the target structure in their L1 is the same when they process their L2. An additional suggestion is to use a language-free measure of WM, such as a digit-span test. The other limitation of this study was that it investigated noticing through an instructional treatment instance only. Further research is needed to verify noticing in other occasions such as in on-line occasions through interaction in input, and in instructed and non-instructed occasions, that is, with or without treatment in input.

In addition, further studies should replicate this study by applying two delayed posttests, one two weeks after treatment, and the other a month after treatment in order to assess maintenance in a longer period of time. Besides, future studies should also replicate this study by assessing other aspects of oral performance during participants' speech, such as fluency, complexity or lexical density.

Based on the findings of this study, some pedagogical implications are proposed for L2 language teachers: (a) design different tasks that call learners' attention to the L2 linguistic formal aspects to be taught,

Organon, Porto Alegre, nº 51, julho-dezembro, 2011, p. 217-243 
(b) provide learners with opportunities to notice instances of formal aspects and instances of grammar structures in input, and (3) make learners aware of what they are learning. Instruction in input probably benefits L2 learners, contributes to both L2 development and better performance of L2 oral tasks.

In addition, some improvement in the oral tasks performance, especially of some lower spans, probably occurred because of the instructional treatment and task repetition in the three test occasions. Initially, task repetition was avoided by shifting the pictures of the maps several times; however, later on, it could not be avoided by only changing pictures each time. The pictures were different, but the oral task was exactly the same at the three tests. Thus, task repetition might be beneficial to L2 oral performance since the frequency and practice of input of the same task (input frequency and task repetition) may contribute to noticing (Ellis \& Schmidt, 1997), to the recalling of noticing, and to language maintenance (Bergsleithner, 2007; Bergsleithner \& Frota, forthcoming) .

In sum, this study can be taken as a contribution to better understand why humans present individuals differences when dealing with a complex cognitive task, such as performing more accurate speech in the L2.

\section{REFERENCES}

BADDELEY, A. D. (1986). Working memory. Oxford: Clarendon Press. BADDELEY, A. D. (1990). Human memory: Theory and practice. Hove, UK: Lawrence Erlbaum Associates.

BADDELEY, A. D., \& Hitch, G. (1974). Working memory. In G. H. Bower (Ed.), The psychology of learning and motivation (pp. 47-89).

New York: Academic Press.

BERGSLEITHNER, J. M. (2007). Working memory capacity, noticing, and L2 speech production. Unpublished doctoral's dissertation. Universidade Federal de Santa Catarina.

BERGSLEITHNER, J. M. (2009). Mas afinal, o que é a Noticing Hypothesis?. Interdisciplinar: Revista de Estudos em Língua e Literatura, v.9, p.101 - 106, 2009.

BERGSLEITHNER \& FROTA, forthcoming. The role of Noticing and Instruction in the enhancement of L2 learning. Paper presented at AAAL 2011 (forthcoming). 
BYGATE, M. (2001). Effects of task repetition on the structure and control of oral language. In M. BYGATE; P. SKEHAN, \& M. SWAIN (Eds.), Researching pedagogic tasks: Second language learning, teaching, and testing. Longman.

COWAN, N. (1988). Evolving conceptions of memory storage, selective attention, and their mutual constraints within the human information processing system. Psychological Bulletin, 104, 163-191.

DANEMAN, M. (1991). Working memory as a predictor of verbal fluency. Journal of Psycholinguistic Research, 20, 445-464.

DANEMAN, M., \& CARPENTER, P. A. (1980). Individual differences in working memory and reading. Journal of Verbal Learning and Verbal Behavior, 19, 450-466.

DANEMAN, M., \& CARPENTER, P. A. (1983). Individual differences in integrating information between and within sentences. Journal of Experimental Psychology: Learning, Memory, and Cognition, 9, 561584.

DANEMAN, M., \& GREEN, I. (1986). Individual differences in comprehending and producing words in context. Journal of Memory and Language, 25, 1-18.

Ellis, N. C., \& Schmidt, R. (1997). Morphology and longer distance dependencies: Laboratory research illuminating the A in SLA. Studies in Second Language Acquisition, 19(2), 145-171.

ELLIS, R. (1990). Instructed second language acquisition. Oxford: Basil Blackwell.

ELLIS, R. (1993). The structural syllabus and second language acquisition. TESOL Quartely, 27 (1), 91-112.

ELLIS, R. (1994). The study of second language acquisition. Oxford: Oxford University Press.

ELLIS, R. (1999). Theoretical Perspectives on Interaction and Language Learning. In R. Ellis (Ed.), Learning a second language through interaction (pp. 3-33). Philadelphia PA: John Benjamins Publishing Company.

ELLIS, R. (2001). Investigating form-focused instruction. Language Learning: 51, 1-46.

ERICSSON, K., \& SIMON, H. (1980). Verbal reports as data. Psychological Review, 87, 215-251.

ERICSSON, K., \& SIMON, H. (1993). Protocol analysis: verbal reports as data ( $2^{\text {nd }}$ ed.). Cambridge, MA: MIT Press.

Organon, Porto Alegre, nº 51, julho-dezembro, 2011, p. 217-243 
FORTKAMP, M. B. M. (1999). Working memory capacity and aspects of L2 speech production. Communication and Cognition, 32, 259-296. FORTKAMP, M. B. M. (2000). Working memory capacity and L2 speech production: An exploratory study. Unpublished doctoral dissertation. Florianópolis: Universidade Federal de Santa Catarina.

FORTKAMP, M.B.M., \& BERGSLEITHNER, J.M. (2007). The relationship among individual differences in working memory capacity, noticing, and L2 speech production. Revista Signo, vol 32, pp. 40-53. HARRINGTON, M. (1992). Working memory capacity as a constraint on L2 development. In R. J. Harris (Ed.), Cognitive Processing in Bilinguals (pp. 123-135). Amsterdam: Elsevier.

HARRINGTON, M., \& SAWYER, M (1992). L2 working memory capacity and L2 reading skill. Studies in Second Language Acquisition, 14, 25-38. JUST, M. A., \& CARPENTER, P. A. (1992). A capacity theory of comprehension: Individual differences in working memory. Psychological Review, 99, 122-149.

LOEWEN, S. (2004). Uptake in Incidental Focus on Form in Meaning-Focused ESL lessons. Language Learning, 54 (1), 153-188. MACKEY, A. (2006) Feedback, Noticing and Instructed Second Language Learning. Applied Linguistics, 27 (3): 405-430.

MACKEY, A. ADAMS, R., STAFFORD, C., \& WINKE, P. (2006). Exploring the relationship between modified output and working memory capacity. Manuscript submitted for publication.

MACKEY, A., \& PHILIP, J. (1998). Conversational Interaction and Second Language Development: Recasts, Responses, and Red Herrings? The Modern Language Journal, 98, 338-356.

MACKEY, A., PHILP, J., FUJII, A., EGI, T., \& TATSUMI, T. (2002). Individual differences in working memory, noticing of interactional feedback and L2 development. In P. Robinson (Ed.), Individual Differences and Instructed Language Learning (pp. 181-208). Philadelphia, PA: John Benjamins Publishing Company.

MIYAKE, A., CARPENTER, P. A., \& JUST, M. A. (1994). A capacity approach to syntactic comprehension disorders: Making normal adults perform like aphasic patients. Cognitive Neuropsyhcology, 11, 671-717. MIYAKE, A., \& FRIEDMAN, N. P. (1998). Individual differences in second language proficiency: working memory as language aptitude. In A. F. Healy, \& L.E. Bourne, Jr. (Eds.), Foreign Language Learning: Psycholinguistic Studies on Training and Retention (pp. 339-364). Ma- 
hawah, N. J: Lawrence Erbaum.

MIYAKE, A., \& SHAH, P. (1999). Models of Working Memory: Mechanisms of Active Maintenance and Executive Control. Cambridge: Cambridge University Press.

MIYAKE, A., \& SHAH, P. (1999). Toward a unified theory of working memory: Emerging general consensus, unresolved theoretical issues, and future research directions. In A. Miyake, \& P. Shah (Eds.), Models of Working Memory: Mechanisms of Active Maintenance and Executive Control (pp. 442-481). Cambridge: Cambridge University Press.

PAYNE, J. S., \& WHITNEY, P. J. (2002). Developing L2 oral proficiency through synchronous CMC: Output, working memory, and interlanguage development. CALICO Journal, 20(1),7 32.

PAYNE, J. S., \& ROSS, B. M. (2005). Synchronous CMC, working memory, and L2 oral proficiency development. Language Learning \& Technology, 9(3), 35-54.

RICHARDS, J., HULL, J. \& PROCTOR, S. (2002). Interchange Book Series. Cambridge University Press.

ROBINSON, P. (1995). Aptitude, awareness, and the fundamental similarity of implicit and explicit second language learning. In R. Schmidt (Ed.), Attention and awareness in foreign language learning (pp.303-357). Honolulu: University of Hawai'i, Second Language Teaching \& Curriculum Center. ROBINSON, P. (1996a). Learning simple and complex second language rules under implicit, incidental, rule-search, and instructed conditions. Studies in Second Language Acquisition, 18, 27-67. ROBINSON, P. (1996b). Consciousness, rules and instructed second language acquisition. New York: Lang.

ROBINSON, P. (1997). Generalizability and automaticity of second language learning under implicit, incidental, enhanced and instructed conditions. Studies in Second Language Acquisition, 19, 223-247.

ROBINSON, P. (2001). Cognition and second language instruction. Cambridge University Press.

ROBINSON, P. (2002a). Effects of individual differences in intelligence, aptitude and working memory on adult incidental SLA: A replication and extension of Reber et al. (1991). In P. Robinson (Ed.), Individual differences and instructed language learning (pp. 211-266). Philadelphia, PA: John Benjamins Publishing Company. ROBINSON, P. (2002b). Individual differences and instructed language 
learning. Philadelphia, PA: John Benjamins Publishing Company. ROBINSON, P. (2005). Aptitude and second language acquisition. Annual Review of Applied Linguistics, 25, 45-73.

SCHMIDT, R. (1990). The role of consciousness in second language learning. Applied Linguistics, 11, 129-158.

SCHMIDT, R. (1995). Consciousness and foreign language learning: A tutorial on the role of attention and awareness in learning. In R. Schmidt (Ed.), Attention and awareness in foreign language learning (pp. 1-63). Mãnoa: Second Language and Curriculum Center, University of Hawai'i at Mãnoa.

SCHMIDT, R. (2001). Attention. Cognition and Second Language Instruction, 3-32.

SCHMIDT, R., \& FROTA, S. N. (1986). "Developing basic conversational ability in a second language: A case study of an adult learner of Portuguese." In R. R. Day, Ed., Talking to learn: conversation in second language acquisition (pp. 237-326). Newbury House.

SHAH, P., \& MIYAKE, A. (1996). The separability of working memory resources for spatial thinking and language processing. An individual differences approach. Journal of Experimental Psychology: General, 125, 4-27.

SKEHAN, P. A. (1989). Individual differences in second-language learning. London: Edward Arnold.

SKEHAN, P. A. (1996). Framework for the implementation of taskbased instruction. Applied Linguistics, 17 (1). Oxford University Press. SKEHAN, P. A. (1998). A cognitive approach to language learning. Oxford: Oxford University Press.

Yoshimura, Y. (2001). THE ROLE OF WORKING MEMORY IN LANGUAGE APTITUDE. IN X. BONCH-BRUEVICH, W. J. Crawford, J. Hellermann, C. Higgins, \& H. Nguyen (Eds.), The past, present, and future of second language research (pp. 144-163). Somerville, MA: Cascadilla Press.

WATANABE, Y., \&. BERGSLEITHNER, J. M. (2006). A Research Synthesis of L2 working memory measurements. In Madden-Wood, Z. and Ueki, K. (Eds.): The 10th Annual Student Conference of the College of Languages, Linguistics, and Literature. Proceedings 2006: Selected Papers from the Tenth College-wide Conference for Students in Languages, Linguistics, and Literature. Honolulu, HI, USA: Distributed by NFLRC, University of Hawai'i at Manoa, v. 0. p. 47-60. 
APPENDIX A

The oral protocol (adapted by Bergsleithner, 2007)

1. Do you notice grammatical rules when the teacher explains? (Você nota as regras gramaticais quando o professor explica?)

( ) yes ( ) no ( ) sometimes

2. Do you look for rules before speaking? (Você procura pelas regras antes de falar?)

$\begin{array}{lll}(\text { ) yes } & (\text { ) no } & \text { ( ) sometimes }\end{array}$

3. Do you remember the rule the teacher explained today? (Você lembra da regra que o professor explicou hoje?)

( ) yes ( ) no ( ) sometimes

4. Can you verbalize the target rule? Talk about the rule. (Você pode verbalizar a regra? Fale sobre a regra com as suas próprias palavras)

5. Give two examples using the rule. (Dê dois exemplos usando a regra que o professor explicou hoje).

P.S.: The oral protocol was administered in Portuguese in order to facilitate the participants' understanding of the questions in the interview.

\section{APPENDIX B \\ Assessment of noticing (Bergsleithner, 2007)}

(i) Scores ranged from 0 to 10 for Noticing 1 (N1) or from 0 to 11 for Noticing 2 (N2)

1. Do you notice any rules when the teacher explains?

0 - no

1 - sometimes

2 - yes

2. Do you look for rules before speaking?

0 - no

1 - sometimes

2 - yes

3. Do you remember the rule the teacher explained today?

0 - no

1 - yes

4. Can you verbalize the target rule? Talk about the rule.

0 - cannot verbalize the target structure

1 - yes, but limited understanding

Organon, Porto Alegre, nº 51, julho-dezembro, 2011, p. 217-243 
2 - yes, seem to understand

5. Give two examples using the rule.

a) 0 (zero) - no example

1 - example, but not really correct

2 - good example

b) 0 (zero) - no example

1 - example, but not really correct

2 - good example

\section{APPENDIX C \\ Parameters to assess the participants' accuracy in the performance of Indirect Questions in the three oral production tasks}

\section{I) Errors considered totally inaccurate}

1. When the verb to be is in the middle and at the end of a sentence, that is, it appears twice in the sentence:

e.g.: Can you tell me what's the bill is ?

e.g.: Could you tell me where is the Port Johnson is ?

2. When the grammatical construction or organization of the sentence is totally wrong, incomprehensible or incoherent:

e.g.: Could you tell stand up in the table and stop shout?

e.g.: Could you tell me the girl in that table is tell your friend about?

3. When the structure of the sentence still shows aspects of direct questions, such as:

e.g.: Could you tell me wherés the Central park?

e.g.: Could you tell me wherès the Park Avenue?

4. When the structure of the sentence still shows aspects of direct questions and problems of verb agreement together.

e.g.: Can you tell me where are $2^{\text {nd }}$ Street?

e.g.: Could you please tell me where are Street 276?

P.S.: In these two examples, not only the position of the main verb is inappropriate, that indicates certain aspects of a direct sentence, but also the verb agreement presents problem with the rest verb of the sentence.

5. When the structure of the sentence presents problems of subject and verb agreement, since this formal aspect makes part of the target structure, and because of that it cannot be considered just as a word choice. 
e.g.: Could you tell me how many peoples in the restaurant is?

P.S.: In this case, besides subject-verb agreement, there is a mistake with "people" instead of "peoples".

6. When it is missing any word in the target structure, for example, could you tell... instead of could you tell me. It is not being considered correct because this shows a grammatical structure problem in the target structure and lack of knowledge about it.

e.g.: Could you tell (???) who put the frog in that meal?

e.g.: Could you tell (???) who ate that fish?

7. When participants use the verb to have instead of to be (is or are), because it is not possible to know how they would use the correct order of the verb there to be. Because of that, it is considered inaccurate.

e.g.: Could you tell me what has in that soup?

8. When the verb tense used in the sentence should be The Present Continuous Tense instead of The Simple Present Tense, because they should use the verb to be, and it is difficult to evaluate if they would know how to accurately use it.

e.g.: Do you know what the couple talks? (instead of is talking)

e.g.: Do you know why the man cries? (instead of is crying)

P.S.: In the first example, there is another mistake besides the verb tense, that is, the lack of the preposition about after the verb, although lack of prepositions is consider a small mistake.

9. When the relative pronoun is changed for another one, when this changing affects with the target structure or with the coherence of the whole sentence.

e.g.: Could you tell me what the manager was?

e.g.: Can you tell me where the man is nice?

10. When the sentences are incomplete, that is, it is missing an important word.

e.g.: Could you tell me how much their (???) is?

11. When the subject is missing in the sentence, since it is difficult to judge if the participant would use the verb to be of the target structure in the correct or incorrect place.

e.g.: Could you tell me please what kind of soup (???) is? (this is missing).

e.g.: Could you confirm please what kind of steak (???) is? (it or this is missing).

12. When the verb to be is missing, since it interferes with the target structure.

e.g.: Could you tell me what the waitress (???) serving?

13. When the interrogative pronoun where is missing, so it interferes with the target structure.

e.g.: Do you know (???) the Bakerly Street is? (where is missing).

14. When they use verb to be and The Simple Past together.

e.g.: Do you know what is happened?

Organon, Porto Alegre, nº 51, julho-dezembro, 2011, p. 217-243 
15. When they make sentences with the modals can and could, but the sentences are not indirect questions, that is, they are direct. In this case, it is missing one sentence since The Indirect Questions have two, one embedded into the other. e.g.: Can you help me to find the Central Park? (this question is direct, not indirect).

\section{II) Small mistakes that were not considered errors. The sentences were considered correct since the participants used the targeted grammatical structure}

1. Definite or indefinite article (if it is missing in the sentence, or if it is used when it is not necessary).

e.g.: Could you tell me where (the) Hudson River is?

e.g.: Could you tell me where (the) Maison house is?

e.g.: Could you tell me what color (???) egg is? (the is missing)

2. Inadequate lexicon.

2.1. Preposition use (inadequate preposition, or if it is missing in the sentence, or if it is used when it is not necessary).

e.g.: Could you tell me who is in the phone? (in instead of on)

2.2. Word choice (if they use an inadequate word or lexicon, since it does not interfere on the meaning of the whole sentence, but it must keep coherent).

e.g.: Could you tell me what the woman is calling?

3. Word missing (since this word does not make part of the target structure).

e.g.: Could you tell me Northen Boulevard is near this Stain Way? ("if" is missing)

4. Word agreement (singular/plural/countable/uncountable).

e.g.: Do you know if there are much people in the restaurant? (many/much)

5. The use of "it" after a relative pronoun, since they were not taught this.

e.g.: Could you tell me what (it) is going on?

6. When the verb tense used in the sentence is changed by another verb tense without interfering in the structure of the verb to be, as for example, The Simple Present Tense changed by The Simple Past or vice-versa.

e.g.: Can you tell me what she lunch? (instead of lunched)

7. When the relative pronoun is changed for another one, since it does not interfere with the target structure or with coherence of the whole sentence. Or, still, when the relative pronoun presents some problems of agreement with the following word, as for example: e.g.: Could you tell me why that three people are going to the hotel? (that instead of those).

e.g.: Could you tell me what the woman is calling? (instead of who or why).

8. When there is a word missing in the sentence that does not interfere with the mean-

Organon, Porto Alegre, n⿳ํㅗ 51, julho-dezembro, 2011, p. 217-243 
ing of the whole sentence and does not make part of the target structure.

e.g.: Could you tell me who is the person she is talking? (talking to or about)

9. When there is a word choice of an adjective ended with gerund (-ing) by another one ended with a participle form (-ed), and vice-versa, since it does not interfere with the target structure.

e.g.: Can you tell me why he is sitted? (instead of sitting)

e.g.: Can you tell me why she is so exciting? (instead of excited)

III) Very accurate sentences (they were considered correct sentences since they were accurate and coherent, and correctly presented the target structure)

e.g.: Do you know what time the restaurant closes?

e.g.: Do you know what the waiter is doing?

e.g.: Could you tell me what time this restaurant closes?

e.g.: Do you happen to know how long the Park Evis is?

P.S.: All the indirect questions should have presented the following structures in the be-

ginning of the questions to be considered accurate:

Can you tell me...?

Could you tell me...?

Would you tell me...?

Do you know...? Do you happen to know...? 